\title{
MUJERES CONSTRUYENDO CIUDAD DESDE EL ARTE CONTEMPORÁNEO
}

\author{
WOMEN BUILDING CITY FROM CONTEMPORARY ART
}

\section{RESUMEN}

Más o menos desde mediados del siglo XIX la ciudad ha experimentado unos cambios que han afectado a los/as ciudadanos/as, como de la misma manera estos/ as lo han hecho en el espacio que habitamos. Estos cambios que se han dado de una forma más o menos natural, por el devenir del tiempo, y otros de manera forzada por las autoridades. Igualmente hay motivos económicos, como el desarrollo de la sociedad capitalista, que han configurado las ciudades, favoreciendo y provocando movimientos migratorios que tal vez no han resultado tan beneficiosos como la población esperaba. El arte actual ha vuelto la vista sobre la ciudad y sobre los fenómenos de transformación y reubicación, buscando fórmulas y posibles soluciones, o al menos visibilizando los problemas que surgen. De entre todas estas experiencias hay un grupo de mujeres artistas cuyo trabajo me interesa especialmente. Ellas trabajan sobre el territorio, la fábrica de lo público, los nuevos barrios, la situación de una vida ficticia donde ya no hay posibilidad de relación, sobre la situación de esos/as nuevos/as ciudadanos/as. Un trabajo social/político que demuestra unas preocupaciones del arte y, pone de manifiesto la función, utilidad y necesidad del arte para la construcción social.

Palabras clave: Sociedad. Política. Arte. Migraciones. Ciudades. Participación. Mujeres.

\begin{abstract}
More or less since the mid-nineteenth century, the city has undergone changes that have affected citizens, as they have done in the same way in the space we inhabit. These changes that have occurred in a more or less natural way, due to the passing of time, and others in a forced way by the authorities. There are also economic reasons, such as the development of capitalist society, that have shaped cities, favoring and causing migratory movements that perhaps have not been as beneficial as the population expected. Current art has turned its sights on the city and on the phenomena of transformation and relocation, looking for formulas and possible solutions, or at least making visible the problems that arise. Among all these experiences there is a group of women artists whose work interests me especially. They work on the territory, the public factory, the new neighborhoods, and the situation of a fictitious life where there is no longer any possibility of relationship, on the situation of those new citizens. A social / political work that demonstrates the concerns of art and highlights the function, utility and necessity of art for social construction.
\end{abstract}

Juan-Ramón Barbancho

Doctor en Historia del Arte por la Universidad de Sevilla. 
Keywords: Society. Politics. Art. Migration. Cities. Participation. Women.

La ciudad es el lugar en el que se entrecruzan vidas y culturas de muchas personas y grupos sociales. Es mucho más que un trazado urbano, edificios públicos y privados, plazas y parques, es más que urbanismo, más que arquitectura. La ciudad representa una cultura, una comunidad de personas definida por los/as ciudadanos/ as. Aunque más que de cultura, deberíamos hablar de culturas porque dentro de un mismo espacio, y atendiendo a la evolución urbanística, social y étnica que estamos viviendo en las últimas décadas, la ciudad ya no es una realidad homogénea, no todos/as vivimos el mismo espacio o no tenemos la misma sensación de él. Además, está pensada, o así parecía serlo, como un espacio para la libertad aunque cada día nos damos cuenta de que esto es una gran falacia.

Pero todo encierra sus peligros, igualmente la ciudad puede ser espacio para la explotación. En ella se ejemplifican, mejor que en cualquier otro lugar, el poder (político) y el capital (como representante de los intereses de ese poder). Hay libertad pero también coerción, autonomía y sometimiento, nuevas posibilidades de crecimiento y situaciones que rayan con lo imposible. Podemos enfrentarnos a problemas que antes ni habíamos imaginado, como también aportar soluciones. Muchas personas han pasado de su vida tranquila en los pueblos a una situación límite en la ciudad y buena prueba de ello son los suburbios, las "nuevas barriadas" que han ido creciendo en el extrarradio, de manera más o menos planificada algunas, absolutamente caótica otras y que han cobrado una enorme extensión -y un gran protagonismo en algunos casos-. Eso por no hablar de las "oscuras intenciones" de mantener a los obreros fuera de los centros urbanos "aseados" y "controlados" para dar una visión de confort a turistas y consumidores. Mike Davis ${ }^{1}$ habla de este fenómeno como Planet of Slums (Planeta de Suburbios), que vemos muy bien reflejados en la obra de algunas artistas que más adelante analizaremos. Mujeres que han hecho de su trabajo un constructo social/político de denuncia, pasando de ser artistas -como coloquialmente se puede entender- a constructoras de sociabilidad.

En este artículo me propongo analizar las obras de algunas mujeres artistas que, desde su trabajo, no sólo han abordado diferentes asuntos sobre la ciudad sino que han trabajado directamente en el espacio y con las personas. Temas en los que se encuentran los problemas de la vivienda, la situación de los y las migrantes, los efectos de una política expansionista que destruye zonas y edificios que son parte de la historia y con los que se identifican los y las habitantes o que son parte de su sustento.

Entre los primeros está el vídeo Habitar (2006) de Angie Bonino (Lima, Perú, 1974), que filmó desalojos en Barcelona y Lima. Ahora se está dando mucha publicidad y protagonismo al tema de los okupas pero se pretende pasar por alto otro tipo de

1 Mike Davis (1946), analista social, teórico urbano, historiador y activista político estadounidense. 
ocupaciones: los desalojos de los bancos, mucho más numeroso y problemático. Bonino pone el dedo en la llaga de esta situación.

Sobre la situación de los y las migrantes trata la obra de artistas como Ingrid W. Merino (Santiago, Chile, 1963). Las periferias no son iguales en todos lados; no es lo mismo estar en los bordes de una ciudad que otra, de un país que otro. No es lo mismo una sociedad que otra. En Dislocación (2010), esas periferias son radicalmente diferentes a otras que podemos imaginarnos. Vistos esos barrios en la obra de Merino podríamos pensar que se trata de urbanizaciones de lujo si los comparamos con otros de Europa o América. Por lo tanto, la situación de quienes allí viven también lo son. Este vídeo está grabado en Suiza y por más que la autora defina estos barrios como auf gesichtslose Agglo-Vorstädte, suburbios de aglomeración sin rostro, esa comparación, sobre todo con las condiciones de vida en otros puntos del planeta, es imposible y tal vez hasta cruel. Las diferencias sociales y las malas condiciones de vida son siempre lamentables, pero también dependen de qué lado estés, de eso no hay duda.

$\mathrm{Su}$ investigación consistió en trasladarse a esas zonas de la ciudad, dejar constancia de lo que allí ocurre y plasmar también ciertas condiciones de vida de emigrantes sin documentos.

En algunas partes del vídeo se ven esos grandes edificios/colmena que vemos en muchas ciudades y en trabajos de otros artistas. Casi podríamos decir que son casas de aglomeración, pero aun así con unas condiciones evidentemente diferentes. No obstante el travelling que hace Merino es muy significativo, la imagen de una cierta segregación parcial con una mirada social.

La videoinstalación Muertos civiles (2009)² de la misma autora aborda el tema de los inmigrantes sin documentos, planteado como un proyecto de investigación. El inicio de este trabajo fue un seminario en el que Ingrid fue invitada por un grupo de mujeres "ilegales" latinoamericanas, para analizar y reflexionar sobre su propia situación en Suiza, lo que contrasta con la situación de los hombres en iguales condiciones.

En el transcurso del seminario, y a través de la propia obra de Merino, podemos diferenciar los diversos problemas que afectan a los diferentes grupos de inmigrantes procedentes de culturas dispares y escuchar la voz de las mujeres.

Creo que es muy significativo el título de la obra, Muertos civiles hace referencia directa a su situación: sin un estatus jurídico, "sin papeles" es como si no fueras nadie, no tienes derechos, estás muerto.

2 "El trabajo con las migrantes ilegales sudamericanas en Zürich, lo comencé con un seminario. Después de una semana de sesiones de documentales sobre ilegalidad de migrantes de diferentes continentes, comenzamos a discutir sobre las diferencias y realidades entre las diferentes realidades de migrante ilegales de un país al otro país.

Las mujeres ilegales que visitaron el seminario tuvieron la oportunidad de criticar ciertas posturas de cineastas y medios de difusión, como también de expresarse críticamente en confronte a las diferencias culturales, étnicas, sexuales, etc. y de todo tipo sobre la ilegalidad.

Todas las mujeres ilegales tuvieron honorarios por las sesiones de crítica y reflexión. El valor de sus honorarios era el mismo que para un crítico de cine". 
Igualmente, Los invisibles (2007) es un vídeo-ensayo suyo que aborda la situación de los emigrantes colombianos en Ginebra. Personas que viven bajo la constante amenaza de ser deportados en cualquier momento. Merino busca dar visibilidad a este problema, al que se le añade un trabajo precario y unos sueldos bajos.

\section{Como explica Merino}

abordo, por esta misma vía, la noción de invisibilidad. ¿Cómo dar visibilidad a individuos que por razones de seguridad o de estabilidad, son obligados al anonimato, a la absoluta discreción, a la invisibilidad social?, ¿De qué modo puede ser relatada esta invisibilidad que induce un sentimiento de inexistencia para aquellos que la experimentan? Filmar es un acto que atestigua lo visible y que compone una manera de hacer visible lo que está disimulado 3 .

Son esos barrios, con migrantes o no, los que se acaban convirtiendo en el cuarto trastero de las ciudades donde se esconde lo que nadie quiere ver. Sobre uno de estos espacios trabajó Celia Macías (Sevilla, España, 1977) en Torreblanca gated community (2009), titulado así como contraposición a las nuevas urbanizaciones cerradas y uniformes. Un proyecto entre arte urbano y talleres de creación que la artista y activista cultural sevillana ha llevado a cabo en Torreblanca, un barrio del extrarradio de Sevilla, en su mayoría de autoconstrucción donde la creatividad de cada vecino/a tiene toda la libertad que le dan sus pocos medios.

El proyecto consistió en el acercamiento del arte actual al barrio, con una población habitualmente muy alejada de los circuitos de la cultura. A través del taller los/as habitantes se acercaron al conocimiento de su propio hábitat y ayudados por Macías y el trabajo en grupo han descubierto una nueva forma, no sólo de ver el arte, sino su propio barrio. El "concurso de fachadas" puso de relieve esta creatividad que comento, destacando elementos singulares y variopintos como fachadas alicatadas con azulejos de cuarto de baño, probablemente reutilizados.

En principio el interés de Macías era acercar el arte contemporáneo a la gente, pero se encontró con una realidad que la impresionó y le hizo descubrir una situación distinta, sobre todo una gente que se interesaba por su barrio y que se acercaban a sus planteamientos, los de la artista, con una mirada diferente, sin complejos, sobre todo sin la mirada sesgada de muchos "entendidos" en arte contemporáneo que no salen nunca de sus torres de marfil.

La A92, la autovía de Andalucía, cerró aún más el barrio con un muro que lo aísla. En este muro colocaron las imágenes de una niña que trepa y desde ahí iniciaron un "recorrido turístico" hasta el "Museo ficticio", pasando por la frutería y la zona comercial, el mercadillo de los sábados y el colegio Santa María de los Reyes y vuelta por las VPO franquistas. Esta zona comercial parece acercarse más a una

3 Declaraciones de Ingrid Merino. 
ciudad de Oriente Medio que de la Sevilla actual. En ese "Museo ficticio" se colocaron reproducciones de obras de otros/as artistas, así se acercaba el arte al barrio y el centro a la periferia.

Macías lo consideró como un proyecto no terminado, sólo era el principio de un trabajo de investigación que la podía llevar a elaborar y descubrir nuevas formas de ver el arte, sobre todo a la luz de estas "nuevas interpretaciones" de la gente del barrio.

Por tanto no es la creación de una obra/objeto, sino una forma de redefinición del arte en el espacio público y de construir ciudad en tanto que es creada por las personas que la hacen/viven.

Las situaciones que provocan las migraciones que se repiten en diferentes puntos del planeta como por ejemplo en la frontera entre México y Estados Unidos, una "delgada línea roja" que marca un antes y un después en la vida de muchos/as. Una frontera física cada vez más cerrada, junto a unas fronteras económicas cada vez más abiertas. Cuando la tierra tiembla (2006) de Gloria Martí habla de esta tremenda situación y lo hace desde dos lugares y puntos de vista diferentes: desde Nueva York, donde los mejicanos son la tercera comunidad hispana más numerosa, después de portorriqueños y dominicanos, y desde el lado mejicano, para comprobar cómo se vive en la tierra de aquellos que en Nueva York están discriminados por diferentes causas. Un trabajo, con dimensión de documental, que analiza pormenorizadamente ambos espacios y situaciones. Como en otras realidades de desplazamientos antes comentadas, también en el pueblo han quedado familias y recuerdos. Madres que reviven y añoran y que dependen del dinero que les envían desde el otro lado.

Todos/as somos "otro" en alguna ocasión y las grades ciudades son el escenario ideal para ello. Todos/as nos hemos visto alguna vez con esa sensación de desvalimiento, imposibilitados/as para hacernos entender. Elena García Jiménez (Madrid, España, 1980) lo retrata muy bien en su trabajo Registro anómalo de recontextualización (2010), una obra multidisciplinar (fotografía tejida, objeto intervenido y obra gráfica) donde en primera persona narra los problemas que presenta una ciudad como Berlín para alguien que llega de fuera. En Richtig deutsch, Cartografía nómada y El documento administrativo en la época de la reproductibilidad técnica, habla respectivamente los impedimentos derivados del hecho lingüístico, la representación subjetiva del espacio y los problemas administrativos.

Como decía al principio "la ciudad existe en muchas formas. En parte es una realidad material, socialmente construida, que habitamos y con la que establecemos una relación sensual y simbólica. Por otra parte, la ciudad también es una representación imaginaria, una construcción simbólico discursiva, producto de nuestra imaginación, y sobre todo, del lenguaje”. A esta construcción simbólica responde En la plaza del Che (2009) de Marisa González (Bilbao, España, 1945) que recoge una protesta universitaria en Bogotá donde tatuaron sus muros, como archivos arqueológicos, con los mitos de sus habitantes. Hay momentos en que ha existido

4 Remendi, Gustavo. Representaciones de la ciudad: apuntes para una crítica cultural (I). H enciclopedia. Uruguay. www.henciclopedia.org.uy 
una simbiosis entre las ideologías que representan y las actividades que contienen, pero con el paso del tiempo estos ritmos se desajustan y la intensidad de su presencia fluctúa según los acontecimientos.

En el vídeo observamos cómo se produce la destrucción simultánea de esos muros universitarios y de las acciones de los estudiantes encapuchados, desprovistos de identidad para intentar evitar que se desmoronen sus mitos. La agresividad de ambas destrucciones quedan apaciguadas por músicas de fondo, permaneciendo el Che tatuado como único espectador solitario.

Decía que en muchos lugares se ha dado y se sigue dando un desarrollo mal entendido que destruye tanto símbolos como formas de subsistencia. Ese desarrollo, tan mal planteado en algunas ocasiones, ha conllevado la destrucción de edificios o elementos que los/as ciudadanos/as consideraban como propios hasta el punto de identificarse con ellos. Las nuevas carreteras y autopistas, expansiones, estaciones de ferrocarril, etc. han destruido muchas veces esos elementos, con lo que ello supone, también, de pérdida patrimonial y de memoria, de elemento aglutinador, y que es algo que los/as ciudadanos/as denuncian como algo inútil.

El Zapillo es un barrio de Almería y en este caso se podría hablar también de un "retroprogreso" en el sentido de que los planes de ampliación y "mejora" de la ciudad destruyen elementos de ésta que aglutinan a todos/as. La misma autora refleja esto en El Zapillo (2002-03), donde se pueden escuchar sus quejas, cómo las chimeneas de las antiguas fábricas, ahora destruidas, eran una señal de identidad de un barrio de obreros nacido alrededor de esos edificios. La autora filma justo el momento en que esas grandes chimeneas son dinamitadas.

En segundo caso, en otro punto diferente del planeta, González grabó Let the people decide (Hong Kong 16.01.2010). Se ve cómo esta ciudad, una de las más desarrolladas del mundo y con más densidad de rascacielos, donde se concentran las grandes marcas y finanzas de Asia, crece constantemente robándole terreno al mar y al campo. Ejecutivos chinos hacen su gimnasia habitual en la azotea de uno de los edificios del centro mientras que abajo, en las calles, hay una gran concentración de ciudadanos/as contra la construcción multibillonaria del tren de alta velocidad que va a destrozar campos y pueblos. Protestan por el horror de esta sociedad ultra desarrollista que está destruyendo la vida rural/tradicional.

Los/as manifestantes llevan las manos juntas simulando que portan arroz, caminan lentamente y se reclinan cada veintiséis pasos, según los kilómetros de longitud del trazado viario, para evocar los campos de cultivo que son destruidos.

Sobre esa vida "moderna y acomodada" de las ciudades trabaja Corinna Schnitt (Duisburg, Alemania, 1964) en Living a beautiful life (2004), donde estudia las carreteras y las vías de comunicación, planteando el acceso a la ciudad como laberinto. En algunas de sus obras busca la implicación de los/as ciudadanos/as, que ellos/as sean los protagonistas y den razón de sus vidas, de su ciudad. En uno de ellos recoge declaraciones de niños norteamericanos sobre cómo se imaginan una vida "más bonita". Convertidos en dos monólogos y puestos de boca de una mujer y un 
hombre adultos, estas visiones infantiles muestran un abismo entre las expectativas de ambos sexos, que, se intuye, serán difíciles de alcanzar.

Do outro lado da cidade (2008), de Gloria Martí y Antoni Abad sigue el deambular por la ciudad de los "motoboys", los mensajeros que recorren la ciudad Sao Paulo cada día. Este trabajo radiografía la inmensa urbe a través de rutas y lugares. El vídeo está compuesto por una serie de entrevistas a estos mensajeros que cuentan sus experiencias y sus problemas, pero a través de los que nosotros nos podemos acercar al día a día de la vida en la ciudad. Con los testimonios de cada uno, narrados en tiempo real, los artistas construyeron el canal MOTOBOY, que se puede seguir en directo en www.megafone.net

De una forma tal vez más poética pero no por ello menos política Nira Pereg (Tel-Aviv, Israel, 1969) se acerca a determinados hechos que ocurren en Jerusalén cada sábado y que transforman determinadas zonas de la ciudad. Sabbath (2008) muestra, como un documento, la clausura de los barrios ultra-ortodoxos y sus alrededores en la víspera del Sabbath. En la mayoría de los casos, el acceso del público a estos distritos se bloquea por medio de barreras temporales que permanecen 24 horas, lo que crea una frontera artificial entre estas áreas y el resto de la ciudad. Las barreras las colocan los vecinos del barrio, con la aprobación y el apoyo de la municipalidad de Jerusalén y la policía. Una vez que se han cerrado no se permiten coches en esas zonas acotadas. La ciudad es topográficamente transformada en dos urbes, con y sin coches, con y sin actividad.

Un ritual que sólo puede ser realizado en una hora indicada y en los lugares designados. Aunque el valor de estas barreras puede aparecer algo provisional es sobre todo simbólico, su presencia es una fuente de fricción y conflicto al delimitar una frontera clara entre lo sagrado y lo profano.

Siguiendo con ese encapsular o delimitar la ciudad para un acontecimiento determinado pero en un contexto y por una razón totalmente diferente Intervenciones en Jueves 5 (2007 y 2008) es un proyecto ciudadano y colectivo, de Celia Macías y Alex Peña en el que han participado una gran cantidad de artistas de muy diversos medios con una consigna clara, hacer de la calle un lugar de creación e interacción entre el espacio, los/as vendedores/as y los/as compradores/as pero sin alterar el sentido del mercado.

Un proyecto de arte público como este, como obra de arte, crea un espacio literario y narrativo en el que se desarrollan historias y vivencias y por tanto está alejado forzosamente de otras prácticas que nada tienen que ver con "lo público", sino que se instalan en él como setas que nadie cultiva y a nadie interesan. El arte público en el siglo XXI debería tener la obligación de crear espacios de interacción comunicativa y participación colectiva. Es un conjunto de prácticas artísticas y culturales que buscan la construcción de lo público desde la memoria histórica del lugar en el que se emplazan, hasta las vivencias y trabajos de sus habitantes, de formas de vida alternativas, tal vez diferentes al resto de la ciudad, como es el caso de

5 El jueves es un mercado tradicional, con siglos de existencia, que se desarrolla todos los jueves del año, menos las fiestas, en la calle Feria, en Sevilla. 
El Jueves. Un espacio, la calle, convertida en zona de chamarileo e intercambio en la que no sólo se compran y venden los objetos más inverosímiles, sino que, más allá de esto, es una forma de entender la vida y las relaciones, algo que apenas ha cambiado en sus muchísimos años de historia ininterrumpida.

Al ocupar este espacio público y hacerlo referente y escenario de las reflexiones y vivencias de los/as ciudadanos/as, todos/as participamos en la creación de ese mercado, también en su carácter más profundo y trascendental. Intervenciones en Jueves retoma la historia no sólo del lugar, si no de sus gentes, de sus formas de vida y de relacionarse, convirtiendo la obra de arte en un producto más del mercadeo, infiltrándose en los puestos, en las esquinas y en las casas.

En este tipo de trabajo está implícita la idea de que la obra genera relaciones no solamente entre artista y observador, sino también con el espacio físico, el conjunto de personas que pueden apreciarla y pueden intercambiar puntos de vista sobre ella. Por supuesto estas relaciones son de naturaleza extremadamente diversa y heterogénea.

Con Intervenciones en Jueves se generan auténticas relaciones entre la obra y el observador público, el paseante y posible comprador, entre un pensamiento y un espacio, entre las ideas del/a artista y un contexto específico.

El mercado y la calle es, por un día, un espacio de diálogo con/desde el arte, un lugar inter-humano. Es decir, un proceso que se da sin depender de una operación comercial, aunque a través de ella. Simplemente necesita de la mediación de un signo, de un objeto, de una imagen que genere diálogo entre las personas.

También poético es Location one E two (2005) que realizó Eva Davidova (Sofía, Bulgaria, 1969), aunque en este caso se trate de una vuelta a la ciudad que la vio nacer y que ella trata de recorrer con la memoria y los sentimientos, introducirse en ella. A través de una serie de fotografías y vídeos va abriéndose camino entre los edificios y entre las paredes, haciéndose una con todo aquello que formó parte de su niñez.

En otro extremo María Alós y Nicolás Dumit Estévez crearon en 2001The Passerby Museum/El Museo Peatonal, un museo itinerante en el que los/as transeúntes de un lugar específico (zonas peatonales altamente transitadas) son invitados/as a aportar objetos personales con el propósito de conformar una colección.

Como proyecto público, buscan llevar el arte directamente a la calle para hacer partícipe de la discusión artística y conceptual de la obra a quien que transite por sus alrededores y no sólo a aquellos/as que frecuentan museos o galerías de arte.

El proceso de donación de "obras" para este museo es gratuito y los objetos son recolectados, clasificados y empaquetados para exponerse en las ciudades en donde se hace el proyecto. Pero el contenido de cada "parada" de este peculiar y antropológico museo se realiza en cada ciudad. Así, se convierte en una especie de escaparate y radiografía de todos/as aquellos/as que deciden participar. De alguna manera se convierte en una cartografía personal de la ciudad.

Alós y Estévez pretenden que los/as donantes se impliquen en este proyecto de "colección pública" y completen este ejercicio visitando el espacio, tanto el día de su inauguración como durante toda su exhibición. Pero no se trata de ir a ver obras 
de arte, o tal vez sí, se trata de encontrarse con ellos/as mismos/as, con su propia historia.

Para poner de manifiesto su imagen institucional ${ }^{6}$, estos artistas multidisciplinares elaboran una documentación, con un texto y audio con los que informan a los/as posibles donantes sobre su filosofía y las formas en la que ofrecen sus servicios. La intervención en cada lugar que ha visitado el "museo" es documentada. Así, las acciones e interacciones que de otra manera tendrían una existencia efímera quedan archivadas para la posteridad en la creciente colección de la institución.

The Passerby Museum/El Museo Peatonal abrió sus puertas por primera vez en la calle 42 de Nueva York, en el corazón de Times Square. El mismo año, la institución se trasladó tres meses a la zona del desaparecido World Trade Center, como parte de Looking In, una muestra organizada por el Lower Manhattan Cultural Council. A principios del 2004, auspiciado por Longwood Art Gallery y el Bronx Council of the Arts, se estableció por meses en el condado del Bronx. Desde ahí un nuevo museo se ha instalado en muchos otros lugares, como La Habana, Santo Domingo, México DF o Madrid.

Hay otra creadora en la que me interesa detenerme ahora, en diferentes trabajos suyos sobre y en la ciudad, en su manera de entenderla e intervenir sobre ella, tanto en su historia como en su presente.

Diana Larrea (Madrid, España, 1972) se implica habitualmente en una serie de proyectos en los que los protagonistas son tanto las calles como las personas que las habitan. Bucea en diferentes espacios de la urbe, aquellos que por una razón u otra se encuentran olvidados y/o degradados, intentando dar con su obra una solución o al menos hacer visibles otras formas de vivir y relacionarse en y con el espacio público.

En 2004 realizó la performance Paso de cebra en el barrio de La Calzada, una zona obrera de Gijón, una de esas zonas de hacinamiento a las que las autoridades parecen haberle vuelto la espalda. En época de la dictadura no había lugares de esparcimiento para los/as ciudadanos/as y ni tan siquiera señales de paso. En aquellos años los propios vecinos pintaron, durante la noche, unos pasos de cebra en las calles principales, como señal de protesta.

El proyecto de Larrea consistió en recrear esta acción pública con diferentes artistas, construyendo una performance en la que cada uno creó un paso de cebra portátil. Así se recordaba aquel suceso y se rendía homenaje a los/as ciudadanos/as que se atrevieron a protagonizarlo.

A este interés responden también trabajos como Bajo el adoquín está el jardín (2003) retomando la vieja consigna de mayo del 68 "bajo los adoquines está la playa”. Fue una labor de alguna manera sugerida por los/as habitantes de Lavapiés, un barrio de Madrid que actualmente es un gran espacio multirracial y multicultural, en el que Larrea cubrió con césped natural una parte del suelo de la plaza de Agustín Lara, creando un lugar de esparcimiento que antes no había.

6 Esa "imagen institucional" es importante porque no se trata sólo de una instalación en un lugar determinado. Se trata de un verdadero museo de los/as paseantes. Es decir, un museo de los/as ciudadanos/as. 
En otros dos vídeos aborda este y otros problemas: La extraña vida de las aguas muertas (2007) y Bajo los cimientos crece la hierba (2008), sobre la evolución de Madrid.

En el primero, como una investigación histórica busca en el pasado de la ciudad aquellas huellas que fueron borradas por el tiempo como arroyos que desaparecieron. Construye en el vídeo el sonido del paisaje superponiendo pasado y presente e intentando reconstruir lo que se perdió.

El segundo es una serie de dibujos de grafito y tinta sobre papel y un vídeo. En él reflexiona cómo las urbes han ido destruyendo poco a poco su entorno natural, fijándose una vez más en Madrid. En este caso recupera los jardines, prados y arboledas de la época de los Austrias basándose en un plano de 1656 de Pedro Texeira y, de la misma forma que en el anterior, lo compara con la actualidad.

En el barrio de Lavapiés, sobre el que ya había trabajado creó en 2010 Calles distinguidas. Para este proyecto primero hizo una cartografía de las calles fijándose en sus nombres y en sus casas. Después recreó la señalética de los nombres de esas vías, cambiando en parte su sentido y el dibujo que aparece en ellas, para denunciar el estado de abandono en que se encontraban. Lavapiés tiene importantes edificios públicos y culturales en su área como el Museo Reina Sofía, La Casa Encendida o el teatro Valle Inclán, pero en el que se evidencia un estado lamentable de dejadez por parte del Ayuntamiento.

También de Larrea, en colaboración con Andrés Senra, es el proyecto Plaza SOLución (2011) en el que ambos hacen un recorrido por Madrid, a modo del flanêur, fijándose en determinadas calles, plazas o esquinas, señalándolas de alguna manera, dando razón de algo y evidenciando situaciones que ya deberían estar resueltas, o bien el deseo de cambio de los ciudadanos y ciudadanas.

Utilizando de nuevo el tipo de placas en las que aparece en nombre de las calles, Larrea y Senra realizan unas nuevas en las que el mensaje se altera, se vuelve menos aséptico y más social, más comunal. En frases como "Ayer estaba indignado, hoy estoy ilusionado", "Mandan los mercados y no los he votado" o "Que el espíritu que ilumina Sol no se apague nunca”, Plaza SOLución encierra toda una declaración de intenciones, una postura nada complaciente con la situación actual y una clara complicidad con el movimiento $15 \mathrm{M}$, asentado en la Puerta del Sol.

Su trabajo reviste un claro sentido social y político, un trabajo de arte público que identifica tanto lugares como pensamientos, deseos y luchas y en el que la ciudadanía se ve representada y llamada a la acción.

Por último, Phnom Penh the city of Penh (2009) de Tal Shoshan (Haifa, Israel, 1969) aborda una forma diferente de ver la ciudad, se adentra en un mensaje de palabras y signos que nos aportan otra interesante visión de las cosas, pero también la del/a extranjero/a que intenta hacerse comprender o más bien comprender/ aprehender la ciudad.

La obra está estructurada en tres fragmentos. Cada uno cuenta una historia mitológica basada en el mito de la ciudad de Phnom Penh. La última parte del tríptico 
es una ficción, algo que nunca ocurrió y que está en base a la historia reciente de Camboya entre 1975-1979.

Además, el vídeo es el resultado de un viaje de la autora, de lo que sintió allí y de los recuerdos que se le quedaron grabados. Es el encuentro entre la viajera, mujer occidental, y la ciudad de Phnom Penh en Camboya. Recuerdos agradables y desagradables a la vez, de pesadez y depresión. Shoshan pasó a través de un viaje personal y así aprendió más sobre la capital y su gente. Allí se encontró con muchas historias diferentes: desde la mitología antigua, la historia pasada y el presente. Al reunir estas historias, la ciudad y su naturaleza se revelan. Durante esta marcha la ambulante y la ciudad se convierten en uno, por eso las vivencias se quedan grabadas de una forma indeleble.

Así vista se convierte en un cruce de historias: el antiguo carácter de Penh, la mujer que fundó la ciudad, la creencia budista de la compasión, que ofrece la redención a través de las raíces del dolor y el sufrimiento, la memoria presente de una nación que sufrió el genocidio y el presente urbano de una ciudad desnuda y herida.

\section{Conclusión}

Como vemos, la ciudad, a lo largo de la modernidad, pero sobre todo desde mediados del siglo pasado, ha experimentado unos cambios que han afectado a los/ as ciudadanos/as, tanto como estos/as lo han hecho a lo que entendemos por urbe, porque, como decía antes, es una agitación del pensamiento que busca su hábitat y lo construye según sus propios intereses, en la medida, también, en que esto es posible. Cambios que se han dado de una forma más o menos natural, por el devenir del tiempo, y otros de manera forzada por las autoridades del momento. También los cambios económicos, el desarrollo de la sociedad capitalista, han configurado las ciudades, favoreciendo y provocando movimientos migratorios que, tal vez, no han resultado beneficiosos para la población, con el abandono de las zonas rurales y sus formas de vida y el hacinamiento en las grandes urbes, con unas condiciones de vida no siempre buenas. Actualmente más del 50\% de la población mundial vive en las ciudades. Se estima que para 2030 será el 60\%.

Las consecuencias de esto a veces no han sido tan buenas como se esperaban, las ofertas de trabajo y la calidad de vida no han sido las esperadas en muchos casos, llevando a situaciones de desarraigo. Esa emigración, especialmente en las últimas décadas ha producido un nuevo tipo de ciudadano/a, el/a migrante, que no siempre es bien recibido.

Esos nuevos cambios y esas nuevas metodologías, también con el desarrollo experimentado en las comunicaciones, hace que la vida en la ciudad sea diferente a como la vivíamos hace veinte o treinta años. Las relaciones entre las personas ya no son las mismas. Los cambios en la concepción del territorio, la expansión y en el concepto de urbe, la aparición de nuevos barrios (nuevas zonas de aglomeración o 
barrios cerrados y ultraprotegidos) donde antes sólo había campos y las políticas de los gobiernos han forzado un nuevo tipo no sólo de espacio, sino en la forma de ser ciudadanos/a. Los mercados van desapareciendo poco a poco y las personas, cada vez más, somos vistos como meros consumidores/as. Los centros históricos, antes señas de identidad cultural, ahora son "parques temáticos del patrimonio", cada vez más vacíos de personas/habitantes obligadas a salir de su hábitat tradicional. Las pequeñas tiendas en las que se conversaba desaparecen cada vez más, dejando paso a los grandes centros comerciales, espacios impersonales, no-lugares, donde el intercambio sólo es ya económico. Los cines, a donde antes íbamos a ver una película, pero también como un ritual socio-cultural, ahora son multicines que no dejan espacio a la relación.

Lo público, ese espacio donde nos es dado encontrarnos, compartir, debatir ha sido transformado, cuando no secuestrado. En muchas ciudades el concepto de plaza ha desaparecido, para transformarse en zonas de control. Nuevos conceptos de urbanismo que han transformado estos espacios en lugares inhóspitos, duros, fríos, imposibles de habitar.

El arte actual, como en muchos otros casos de interés social/político, ha vuelto la vista sobre la ciudad y sobre los fenómenos de transformación, buscando fórmulas y posibles soluciones, o al menos visibilizando los problemas que surgen. Estas mujeres de las que hablo, como también muchos hombres, trabajan sobre estos postulados, sobre el territorio, sobre la fábrica de lo público, sobre los nuevos barrios, sobre la situación de una vida ficticia donde ya no hay posibilidad de relación, sobre la situación de esos/as nuevos/as ciudadanos/as. Este interés, además, evidencia unas preocupaciones del arte que deberían ser las de todos/as y, por supuesto, pone de manifiesto la función, utilidad y necesidad del arte para la construcción social/ política.

\section{Bibliografía}

BARBANCHO Rodríguez, Juan-Ramón. Intervenciones en jueves. Catálogo de Intervenciones en jueves. Sevilla: Ed. Ayuntamiento de Sevilla. Distrito Casco Antiguo, 2008.

BARBANCHO Rodríguez, Juan-Ramón Travelling city. Quito: Pontificia Universidad Católica del Ecuador, 2015.

BOLLNOW, Friederich. Hombre y espacio. Barcelona: Biblioteca Universitaria Labor, 1969.

BOURRIAUD, Nicolas. Estética relacional. Los sentidos/artes visuales. Buenos Aires, Argentina: Adriana Hidalgo Editora, Seg. Edición. 2008. 
DUQUE, Félix. Arte público y espacio político. Madrid: Ediciones Akal, 2001.

FISCHER, Ernst. La necesidad del Arte. Madrid: Nexos, 1993.

MÉNDEZ, Lourdes. Antropología de la producción artística. Madrid: Síntesis, 1995.

Recebido em 13/10/2020.

Aceito em 30/11/2020. 